\title{
ÍNDICES DE ÁREA VERDE E COBERTURA VEGETAL DAS PRAÇAS PÚBLICAS DA CIDADE DE GURUPI, TO
}

\author{
Allan Deyvid Pereira da Silva ${ }^{1 *}$, André Ferreira dos Santos ${ }^{2}$, Lucicléia Mendes de Oliveira ${ }^{3}$ \\ ${ }^{1}$ Universidade Federal do Tocantins, Programa de Pós-Graduação em Ciência Florestal e Ambiental, Gurupi, Tocantins, Brasil - \\ allantecnologoagroindustrial@ hotmail.com* \\ ${ }^{2}$ Universidade Federal do Tocantins, Curso de Engenharia Florestal, Gurupi, Tocantins, Brasil - andrefs@uft.edu.br \\ ${ }^{3}$ Universidade Federal de Goiás, Programa de Pós-Graduação em Ciências Ambientais, Goiânia, Goiás, Brasil - lucicleia @ biologa.bio.br
}

Recebido para publicação: 28/02/2015 - Aceito para publicação: 14/06/2016

\begin{abstract}
Resumo
O presente trabalho objetivou estudar as praças públicas de Gurupi por meio dos cálculos dos índices de áreas verdes e cobertura vegetal. Com auxílio de uma trena, obtiveram-se as medidas das praças e da projeção das copas das árvores. Através do programa Google Earth, foram determinadas as áreas dos setores e do perímetro urbano. Com as medidas, fez-se a classificação das praças quanto a Parque de Vizinhança e Parque de Bairro. Posteriormente realizaram-se os cálculos dos índices de Área Verde Total (IAVT), Área Verde para Parques de Vizinhança (IAVPV), Área Verde para Parques de Bairro (IAVPB), Área Verde por Setor (IAVS), Cobertura Vegetal (ICV) e Percentual de Cobertura Vegetal (PCV). Foram obtidos os seguintes resultados: 11 Parques de Vizinhança e 5 Parques de Bairro, sendo que a praça Waldir Lins apresentou a maior área e o setor com maior área verde foi o Central. O IAVT calculado foi de 1,46, o IAVPV foi de 0,58, o IAVPB foi de 0,88 . O maior IAVS foi observado no setor Jardim São Lucas, e o menor, no setor Central. O ICV foi de 0,48 e o PCV, de 0,13 .

Palavras-chave: Parque de vizinhança; parque de bairro; espaços livres públicos.
\end{abstract}

\begin{abstract}
Study of green area index and vegetation cover of squares in the Gurupi city, TO. This study aimed to investigate the public squares of Gurupi through index calculations of green areas and vegetation index. Using tape measure were obtained the measures of the squares and the projection of the treetops. Through the Google Earth program were determined the Neighborhood areas and urban perimeter. By the measures, it was made the classification of squares as Vicinity Park and Neighborhood Park. Subsequently were carried out the calculations of the indexes: total green area (IAVT), green area for vicinity parks (IAVPV), green area for neighborhood parks (IAVPB), green area per sector (IAVS), vegetation cover (ICV) and percentage of vegetation cover (PCV). The following results were obtained: 11 vicinity parks and 5 neighborhood parks, the Waldir Lins square presented the largest area and Central sector presented the largest green area. The calculated IAVT was 1.46 , the IAVPV was 0.58 , the IAVPB was 0.88 . Was observed the highest IAVS in Jardim São Lucas sector and the lowest in the Central sector. ICV was 0.48 and PCV 0.13.

Keywords: Vicinity park; neighborhood park; public open spaces.
\end{abstract}

\section{INTRODUÇÃO}

A criação e manutenção de áreas verdes urbanas são sempre defendidas pela sua capacidade de proporcionar à população melhores condições ambientais. Essas áreas exercem papel positivo na qualidade de vida das pessoas, devido às suas funções sociais, ecológicas, estéticas e educativas, agindo como fator amenizador das condições negativas da urbanização (BARGOS; MATIAS, 2011; RIBEIRO et al., 2013; MARTINI et al., 2014), pois oferecem a possibilidade de lazer e recreação a céu aberto para a população, minimizando fatores estressantes, como ruído, calor e poluição do ar (COSTA, 2010).

Entretanto, o conceito teórico do termo "área verde" ainda é uma questão controversa, pois a definição de quais espaços são realmente considerados áreas verdes geram dificuldades de compreensão dessa temática. Assim, a falta de concordância conceitual causa uma série de conflitos sobre o processo de avaliação da vegetação dos municípios, prejudicando a comparação entre as pesquisas realizadas (COSTA; COLESANTI, 2011; BARGOS; MATIAS, 2011).

Diante dessa questão conceitual, Bargos e Matias (2011) puderam concluir, com auxílio de uma revisão de literatura, que as áreas verdes podem ser definidas como uma categoria de espaço livre urbano composto por

FLORESTA, Curitiba, PR, v. 46, n. 3, p. 353 - 361, jul. / set. 2016.

Silva, A. D. P. da et al.

ISSN eletrônico 1982-4688

DOI: $10.5380 /$ rf.v46i3.40052 
vegetação arbórea e arbustiva, onde pelo menos $70 \%$ da área seja permeável, de acesso público ou não, e que cumpram funções ecológicas, estéticas e de lazer.

As áreas destinadas a lazer e recreação a céu aberto foram classificadas, por intermédio da Conferência Permanente dos Diretores de Parques e Jardins da República Federativa da Alemanha, em Parque de Vizinhança, Parque de Bairro, Parque Distrital ou Setorial e Parque Regional, entre outras categorias. A classificação pode levar em conta diversos fatores, como disponibilidade de área por habitante, distância dela até as residências, propriedade (privada ou pública), bem como sua área total (CAVALHEIRO; DEL PICCHIA, 1992).

A responsabilidade de planejar, criar e gerir esses espaços de singular importância para o bem-estar social é do poder municipal, sendo que a gestão e o planejamento das áreas verdes urbanas devem estar previstas no Plano Diretor. No entanto, um dos problemas encontrados nos planos é a falta de concisão e objetividade, já que apresenta conceitos muito abrangentes de área verde, os quais, geralmente, englobam praças, jardins, unidades de conservação, canteiros centrais de ruas e avenidas, trevos e rotatórias de vias públicas. Além disso, muitos desses locais não apresentam características mínimas que os enquadrem dentro do conceito de área verde, como vegetação e condição mínima para o lazer e a recreação (LONDE; MENDES, 2014).

O Plano Diretor de Desenvolvimento Sustentável de Gurupi foi instituído pela Lei Complementar Municipal $n^{\circ}$ 009/07, e nele é ordenado que nas zonas residenciais deverá ser obedecida a metragem de área verde por habitante recomendada pela Organização Mundial de Saúde (OMS). Todavia o texto não faz menção ao referido valor (GURUPI, 2007). De acordo com De Arruda et al. (2013), o valor recomendado pela OMS é de $12 \mathrm{~m}^{2}$ de área verde por habitante da zona urbana. Esse valor, no Brasil, tem sido atribuído à OMS e à Organização das Nações Unidas (ONU), todavia Cavalheiro e Del Picchia (1992), após enviarem cartas a essas organizações para se cientificarem do assunto, constataram que elas desconhecem o valor citado.

Após revisões, supõe-se que esse valor adotado no Brasil $\left(12 \mathrm{~m}^{2}\right)$ deve ter surgido da referência para parque de bairro e distritais ou setoriais empregados na Alemanha, já que lá é recomendado para essas áreas um total de $13 \mathrm{~m}^{2}$, sendo $6 \mathrm{~m}^{2}$ atribuídos para parques de bairro e $7 \mathrm{~m}^{2}$ para parques distritais no geral (CAVALHEIRO, 1982). Mediante a falta de consenso nacional acerca da referida recomendação, esta pesquisa reportou-se aos trabalhos realizados fora do país, os quais mencionam que o valor aceito é outro (SINGH et al., 2010; FUADY; DARJOSANJOTO, 2012; NOOR et al., 2013; KARAGIANNIS et al., 2014). Assim, o recomendado pela OMS, segundo os referidos autores, é que a zona urbana deva ter um mínimo de $9 \mathrm{~m}^{2}$ de área verde por habitante, sendo que o índice ideal fica compreendido no intervalo de $10 \mathrm{a} 16 \mathrm{~m}^{2}$.

Paralelamente aos supostos valores atribuídos às organizações internacionais, a Sociedade Brasileira de Arborização Urbana (SBAU) também faz recomendações para o índice de área verde. Ela preconiza um mínimo de $15 \mathrm{~m}^{2}$ /habitante para que as áreas verdes públicas destinadas a recreação venham a cumprir plenamente suas funções social e ambiental de fornecer bem-estar, lazer, recreação, isolamento acústico e microclima, entre outros benefícios (LUCON et al., 2013).

Diante do exposto, segundo Nucci (2001), é recomendado considerar áreas verdes públicas aquelas localizadas na zona urbana e que estão ligadas ao uso direto da população residente nessa área, as quais são compostas, geralmente, por parques, jardins ou praças. Nesse sentido, e levando em conta a carência de informações acerca das áreas verdes da cidade de Gurupi, Tocantins, a presente pesquisa tem por objetivo caracterizar as áreas de praças públicas municipais por meio dos seguintes índices: a) índice de área verde total; b) índice de área verde para parque de vizinhança; c) índice de área verde para parque de bairro; d) índice de área verde por setor e) índice de cobertura vegetal; e f) percentual de cobertura vegetal.

\section{MATERIAL E MÉTODOS}

A sede municipal de Gurupi encontra-se localizada entre as coordenadas $11^{\circ} 43^{\prime} 45^{\prime \prime} \mathrm{S}$ e $49^{\circ} 04^{\prime} 07^{\prime \prime} \mathrm{O}$, com altitude média de 287 metros, cujo território perfaz uma área de 1.836,091 km² e está localizado a sudoeste do estado do Tocantins, a $223 \mathrm{~km}$ da capital (Palmas) (SEPLAN, 2013).

Pela classificação climática de Thornthwaite, o clima de Gurupi é do tipo C2wA'a”, caracterizado por um clima úmido subúmido com moderada deficiência hídrica no inverno, evapotranspiração potencial média anual de $1.500 \mathrm{~mm}$, distribuindo-se no verão em torno de $420 \mathrm{~mm}$ ao longo dos três meses consecutivos com temperatura mais elevada (TOCANTINS, 2012). A temperatura média anual é de $29,5^{\circ} \mathrm{C}$, com precipitação anual de $1.804 \mathrm{~mm}$, caracterizada por um inverno seco e um verão chuvoso (DA SILVA et al., 2007). Os solos predominantes no município são os Latossolos, entretanto a área urbana está localizada em uma região com predominância de Argissolos (SEPLAN, 2013).

De acordo com o Instituto Brasileiro de Geografia e Estatística (IBGE) (2010), Gurupi possui uma população de 76.755 habitantes, sendo 75.000 residentes na zona urbana e 1.755 na zona rural, com uma densidade demográfica de $41,8 \mathrm{hab} / \mathrm{km}^{2}$. A cidade possui 44 setores ou bairros, dos quais 12 apresentam pelo menos uma praça, num total de 16 praças, as quais foram objeto deste estudo (Figura 1). 


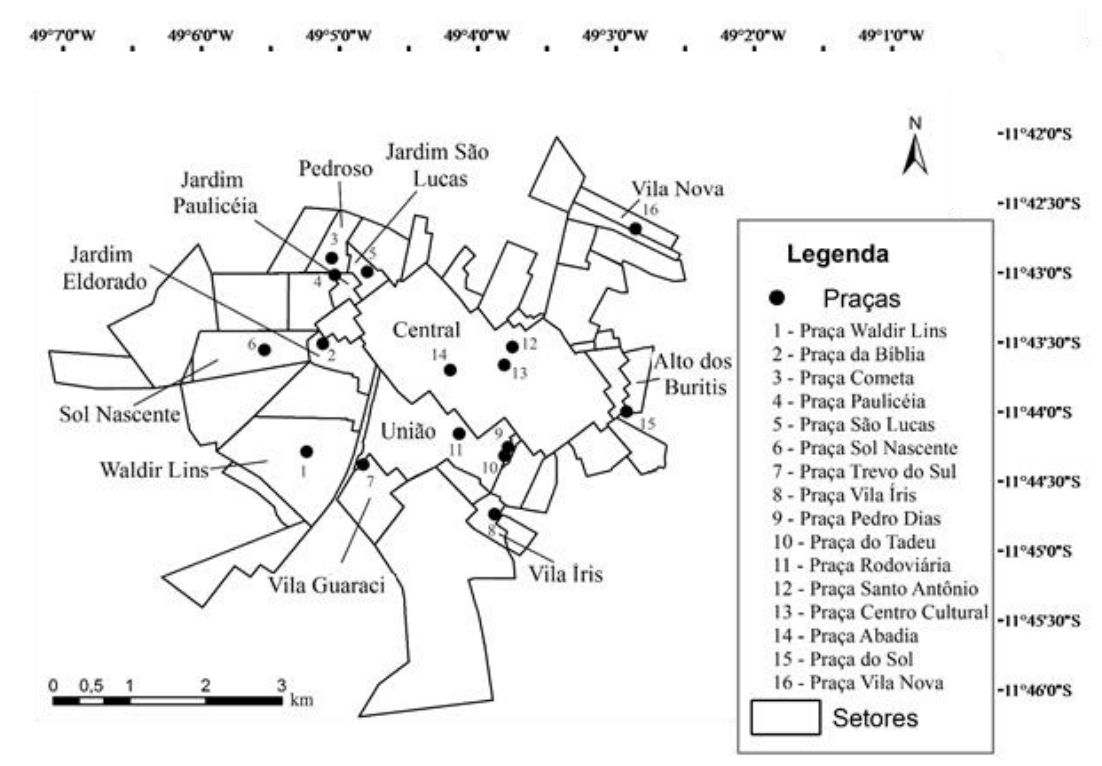

Figura 1. Localização dos 12 setores e das 16 praças estudadas em Gurupi, TO. Adaptado de Gurupi (2016). Figure 1. Location of the 12 sectors and 16 public parks studied in Gurupi, TO. Adapted from Gurupi (2016).

As áreas verdes públicas de Gurupi são representadas por um parque municipal (Parque Mutuca) e praças públicas, no entanto, para o presente estudo, foram consideradas apenas as praças. Para a identificação dessas praças, foi solicitada junto à secretaria de infraestrutura do município uma lista constando o nome e a localização de cada uma delas. De posse desse documento, foi realizada uma visita prévia, para o conhecimento da área e posterior planejamento das atividades.

Neste trabalho foi empregada a metodologia utilizada por Harder et al. (2006), que consideraram a dimensão total das áreas destinadas a lazer e recreação a céu aberto como requisito para classificá-las em Parques de Vizinhança ou Parques de Bairro. Foram identificadas como "Parques de Vizinhança" as praças cuja área total teve dimensão inferior a $10.000 \mathrm{~m}^{2}$, enquanto que as praças com área maior ou igual a $10.000 \mathrm{~m}^{2} \mathrm{e}$ menor que $1.000 .000 \mathrm{~m}^{2}$ foram identificadas como "Parques de Bairro".

Os setores da cidade foram codificados com a letra " $\mathrm{S}$ ", e as áreas estudadas, com as letras "S" e "A", com $\mathrm{S}$ representando o setor no qual está inserida a área (praça) e "A" a própria área de estudo (Tabela 1).

Tabela 1. Codificação dos setores e das áreas estudadas na cidade de Gurupi, TO, 2014.

Table 1. Sectors and studied areas codification, in Gurupi, TO, 2014.

\begin{tabular}{llll}
\hline Setor & & Área & \\
\hline Nome & Código & Nome & Código \\
\hline Auto dos Buritis & S1 & Praça do Sol & S1A1 \\
Setor Vila Nova & S2 & Praça Vila Nova & S2A1 \\
Jardim Paulicéia & S3 & Praça Paulicéia & S3A1 \\
Jardim São Lucas & S4 & Praça São Lucas & S4A1 \\
Setor Pedroso & S5 & Praça Cometa & S5A1 \\
Jardim Eldorado & S6 & Praça da Bíblia & S6A1 \\
Sol Nascente & S7 & Praça Sol Nascente & S7A1 \\
Waldir Lins & S8 & Praça Waldir Lins & S8A1 \\
Setor União & S9 & Praça da Rodoviária & S9A1 \\
Setor União & S9 & Praça Pedro Dias & S9A2 \\
Setor União & S9 & Praça do Tadeu & S9A3 \\
Vila Guaraci & S10 & Praça Trevo Sul & S10A1 \\
Vila Íris & S11 & Praça Vila Íris & S11A1 \\
Central & S12 & Praça Santo Antônio & S12A1 \\
Central & S12 & Praça Centro Cultural & S12A2 \\
Central & S12 & Praça Abadia & S12A3 \\
\hline
\end{tabular}

FLORESTA, Curitiba, PR, v. 46, n. 3, p. 353 - 361, jul. / set. 2016

Silva, A. D. P. da et al.

ISSN eletrônico 1982-4688

DOI: $10.5380 /$ rf.v46i3.40052 
A pesquisa de campo para coleta dos dados da vegetação e dimensionamento das áreas verdes ocorreu durante os meses de agosto a outubro de 2014. Foi realizada a medição da vegetação arbórea considerando-se todos os indivíduos, sejam mudas ou adultos. Com auxílio de uma trena, foram feitas as medições dos diâmetros de copa e perímetros das praças.

Para o diâmetro da copa, inicialmente foram anotadas as medidas aferidas nos sentidos norte para sul e leste para oeste, para subsidiar os cálculos de cobertura vegetal. Posteriormente foi obtido o raio médio para cada árvore, e na sequência foi realizado o cálculo da área sombreada, por meio da equação: $\mathrm{CV}=\Pi \cdot \mathrm{r}^{2}$, em que $\mathrm{CV}$ significa cobertura vegetal. Assim, a cobertura vegetal total foi obtida por meio da somatória da área de cada projeção da copa de árvore avaliada, enquanto os perímetros de cada uma das praças foram utilizados para depois serem calculadas as suas respectivas áreas.

Na medição da área dos setores e área urbanizada, para os cálculos do Índice de Área Verde por Bairro e do Percentual de Cobertura Vegetal, foi utilizado o programa Google Earth (GOOGLE, 2013), com a demarcação de polígono junto ao perímetro dos setores e da área que compõe a parte urbanizada do município de Gurupi.

Os índices aplicados neste trabalho obedeceram à metodologia proposta por Harder et al. (2006), e todas as medidas de área empregadas nos cálculos dos índices foram sob a unidade de medida metro quadrado $\left(\mathrm{m}^{2}\right)$. Os índices avaliados foram:

a) Índice de Área Verde Total (IAVT)

$$
\text { IAVT }=\frac{\sum \text { das áreas totais das praças }}{\mathrm{N}^{\mathrm{o}} \text { de habitantes da área urbana }}
$$

b) Índice de Áreas Verdes para Parque de Vizinhança (IAVPV)

$$
\text { IAVPV }=\frac{\sum \text { das áreas de parques de vizinhança }}{\mathrm{N}^{\mathrm{o}} \text { de habitantes da área urbana }}
$$

c) Índice de Áreas Verdes para Parque de Bairro (IAVPB)

$$
\text { IAVPB }=\frac{\sum \text { das áreas de parques de bairro }}{\mathrm{N}^{\mathrm{o}} \text { de habitantes da área urbana }}
$$

d) Índice de Área Verde por bairro (IAVS)

$$
\text { IAVS }=\frac{\sum \text { das áreas das praças de cada setor }}{\text { Área total do setor }}
$$

e) Índice de Cobertura Vegetal (ICV)

$$
\mathrm{ICV}=\frac{\sum \text { das áreas de copa }}{\mathrm{N}^{\mathrm{o}} \text { de habitantes da área urbana }}
$$

f) Percentual de Cobertura Vegetal (PCV)

$$
\mathrm{PCV}=\frac{\sum \text { das áreas das copas }}{\text { Área urbana do município }} \times 100
$$

\section{RESULTADOS E DISCUSSÃO}

Constatou-se na cidade de Gurupi uma predominância de Parques de Vizinhança (PV) (68,75\%), frente aos Parques de Bairro (PB) (31,25\%) (Tabela 2). De acordo com Lima e Amorim (2011), isso se deve ao histórico descompromisso no planejamento dos loteamentos, em que são destinadas pequenas parcelas da malha urbana para construção de praças e parques. Esse comportamento também pode ser observado nas cidades de Vinhedo, SP, com 86,36\% de Parques de Vizinhança e 13,64\% de Parques de Bairro (HARDER et al., 2006), e Altamira, PA, com 93\% de Parques de Vizinhança e 7\% de Parques de Bairros (DE SOUZA et al., 2014).

Mesmo com número maior de PV, a maior parte do território estudado é de PB (60,3\%) (Tabela 2). Isso se dá em decorrência de as áreas de $\mathrm{PB}$ serem maiores que as de PV (PV $<10.000 \mathrm{~m}^{2}$; $10.000 \mathrm{~m}^{2} \leq \mathrm{PB}<1.000 .000 \mathrm{~m}^{2}$ ). Assim, mesmo em menor número, representaram maior território. 
Tabela 2. Classificação e frequência de ocorrência das praças de Gurupi, TO, em parque de vizinhança e parque de bairro, conforme suas dimensões de áreas.

Table 2. Classification and frequency of occurrence of public parks, at Gurupi, TO, as vicinity park and neighborhood park, according to their dimensions.

\begin{tabular}{|c|c|c|c|}
\hline Classificação e frequência relativa (\%) & Áreas de estudo & Área $\left(\mathrm{m}^{2}\right)$ & Área $(\%)$ \\
\hline \multirow{11}{*}{ Parque de Vizinhança } & S1A1 & $3.912,0$ & 3,58 \\
\hline & S2A1 & $1.758,3$ & 1,61 \\
\hline & S3A1 & $5.588,4$ & 5,11 \\
\hline & S4A1 & $3.721,5$ & 3,40 \\
\hline & S5A1 & $7.893,8$ & 7,22 \\
\hline & S6A1 & $5.952,4$ & 5,44 \\
\hline & S9A2 & $1.024,3$ & 0,94 \\
\hline & S9A3 & $1.575,0$ & 1,44 \\
\hline & S10A1 & $5.164,1$ & 4,72 \\
\hline & S11A1 & 807,4 & 0,74 \\
\hline & S12A3 & $6.029,1$ & 5,51 \\
\hline 68,75 & 11 & $43.426,3$ & 39,7 \\
\hline \multirow{5}{*}{ Parque de Bairro } & S7A1 & $10.693,5$ & 9,78 \\
\hline & S8A1 & $21.649,8$ & 19,80 \\
\hline & S9A1 & $11.881,3$ & 10,87 \\
\hline & S12A1 & $10.536,7$ & 9,64 \\
\hline & $\mathrm{S} 12 \mathrm{~A} 2$ & $11.164,2$ & 10,21 \\
\hline 31,25 & 5 & $65.925,5$ & 60,3 \\
\hline 100,0 & 16 & 109351,8 & 100,0 \\
\hline
\end{tabular}

O PB que apresentou maior dimensão foi a praça Waldir Lins (S8A1) (21.649,8 m²) (Tabela 2). Mesmo essa área sendo a maior área verde constatada neste estudo, nota-se, na figura 2, que a ela não apresenta maiores recursos para lazer e que sua arborização ainda é jovem. Portanto, trata-se de uma área com grande potencial para desenvolvimento de um projeto paisagístico futuro, tendo em vista que as plantas estão jovens e há espaço para a inclusão de mais árvores, bem como de equipamentos para favorecer o lazer dos visitantes.

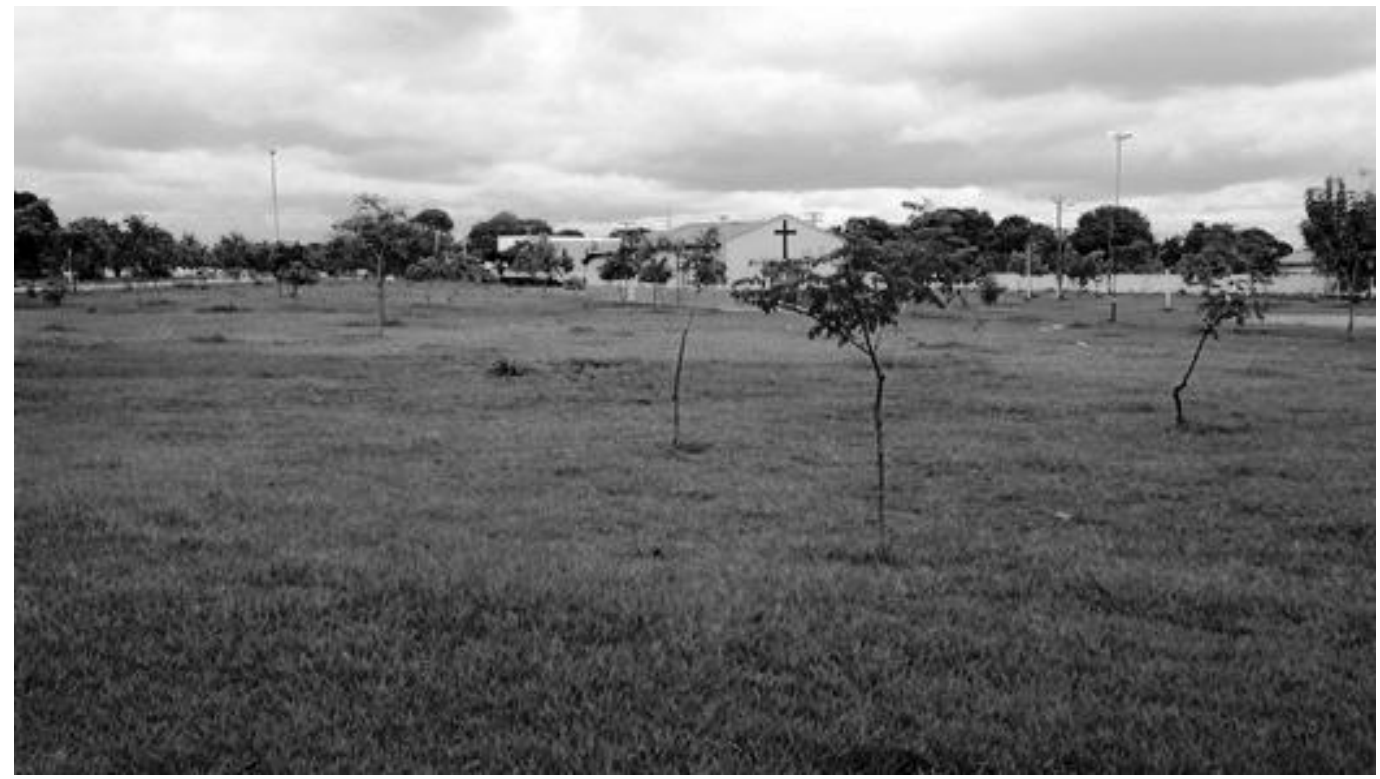

Figura 2. Praça Waldir Lins (S8A1) com arborização jovem e mostrando a escassez de equipamentos. Figure 2. Waldir Lins park (S8A1) presenting young afforestation and equipment shortage. 
O Setor Central (S12) apresentou maior área de praça, perfazendo um total de $27.730 \mathrm{~m}^{2}$ (Tabela 3). Isso se deve ao fato de nesse setor estarem localizadas as três principais praças da cidade (S12A1, S12A2, S12A3) (Tabela 1) e por ser o maior (Tabela 4) e mais velho do município.

Os setores S1, S2, S3, S4, S5, S6, S10 e S11 apresentaram apenas PV, S7 e S8 tiveram somente PB, enquanto em S9 e S12 existem tanto PV quanto PB. Isso se dá devido a S9 e S12, bem como S7 e S8, serem os quatro maiores setores com presença de praças na cidade (Tabela 4).

Tabela 2. Área de Parque de Vizinhança (PV) e Parque de Bairro (PB) por Setor, em Gurupi, TO, 2014.

Table 3. Areas of Vicinity Park (PV) and Neighborhood Park (PB) by sector in Gurupi, TO, 2014.

\begin{tabular}{lrrr}
\hline Setor & $\mathbf{P V}\left(\mathbf{m}^{\mathbf{2}}\right)$ & $\mathbf{P B}\left(\mathbf{m}^{\mathbf{2}}\right)$ & Total $\left(\mathbf{m}^{\mathbf{2}}\right)$ \\
\hline S1 & $3.912,0$ & 0 & $3.912,0$ \\
S2 & $1.758,3$ & 0 & $1.758,3$ \\
S3 & $5.588,4$ & 0 & $5.588,4$ \\
S4 & $3.721,5$ & 0 & $3.721,5$ \\
S5 & $7.893,8$ & 0 & $7.893,8$ \\
S6 & $5.952,4$ & 0 & $5.952,4$ \\
S7 & 0 & $10.693,5$ & $10.693,5$ \\
S8 & 0 & $21.649,8$ & $21.649,8$ \\
S9 & $2.599,3$ & $11.881,3$ & $14.480,6$ \\
S10 & $5.164,1$ & 0 & $5.164,1$ \\
S11 & 807,4 & 0 & 807,4 \\
S12 & $6.029,1$ & $21.700,9$ & $27.730,0$ \\
Total $\left(\mathbf{m}^{\mathbf{2}}\right)$ & $\mathbf{4 3 . 4 2 6 , 3}$ & $65.925,5$ & $109.351,8$ \\
\hline
\end{tabular}

A cidade de Gurupi possui 109.351,72 $\mathrm{m}^{2}$ de área verde formada por praças (Tabela 3). Seu IAVT calculado foi de $1,46 \mathrm{~m}^{2}$ /habitante. O valor de IAVT de Gurupi é semelhante ao observado em Goiandira, GO (1,29) (PIRES et al., 2010), inferior ao de Vinhedo, SP (2,19) (HARDER et al., 2006), entretanto é superior aos de Altamira, PA (0,87) (DE SOUZA et al., 2014), Mossoró, RN (0,57) (DE ARRUDA et al., 2013) e Teresina, PI $(0,86)$ (CARVALHO et al., 2007). Dessa forma, os IAVT's variam de uma cidade para outra, contudo Gurupi apresenta valor maior que a maior parte dos encontrados nos trabalhos consultados. Em linhas gerais, os resultados desta pesquisa e as demais estudadas encontram-se abaixo do valor ideal estipulado pela SBAU $\left(15 \mathrm{~m}^{2}\right)$ para áreas verdes públicas destinadas a recreação (LUCON et al., 2013). Se compararmos ao "suposto" índice recomendado pela ONU ou OMS citado no Brasil $\left(12 \mathrm{~m}^{2}\right.$ ) (DE ARRUDA et al., 2013), ou mesmo ao valor mínimo também recomendado pela OMS citado por pesquisadores internacionais $\left(9 \mathrm{~m}^{2}\right.$ ) (SINGH et al., 2010; FUADY; DARJOSANJOTO, 2012; NOOR et al., 2013; KARAGIANNIS et al., 2014), as áreas verdes de Gurupi ainda estão muito aquém do ideal, necessitando de criação de novas áreas.

Foi constatada uma área de 43.426,3 $\mathrm{m}^{2}$ de PV em Gurupi (Tabela 3), resultando em um IAVPV de $0,58 \mathrm{~m}^{2} /$ habitante. Na cidade de Vinhedo, esse índice foi maior $(0,65)$ (HARDER et al., 2006) e em Altamira foi menor (0,54) (DE SOUZA et al., 2014). De modo geral, nota-se que o IAVPV de Gurupi não apresentou grande diferença quando comparada às demais cidades, mostrando uma similaridade desse tipo de área com os demais municípios estudados. Embora não haja uma recomendação específica de valor ideal de IAVPV, sugere-se sempre a criação de novas áreas, em razão da sua importante função social. Os PV's são áreas de grande importância para a qualidade de vida urbana, pois subsidiam as atividades relacionadas ao convívio e ao lazer cotidiano (DOS SANTOS, 2011).

A área total de PB encontrada em Gurupi foi de $65.925,5 \mathrm{~m}^{2}$ (Tabela 3) e o IAVPB calculado foi de $0,88 \mathrm{~m}^{2} /$ habitante. No Brasil não há uma recomendação de valor ideal para esse tipo de área, mas, de acordo com Cavalheiro (1982), na Alemanha recomenda-se um IAVPB de $6 \mathrm{~m}^{2} /$ habitante. Dessa forma, se compararmos com o valor estipulado na Alemanha, Gurupi tem um IAVPB longe do ideal, sendo necessária a criação de novas áreas de PB para atender a recomendação. Valor maior para IAVPB foi constatado na cidade de Vinhedo $(1,55)$ (HARDER et al., 2006), entretanto, em Altamira o valor foi menor (0,31) (DE SOUZA et al., 2014). Para Dos Santos (2011), as áreas de PB exercem importante função social na cidade, incluindo aquelas de interesse comunitário, de conservação ambiental e de recreação, entre outros usos.

Para compreender a distribuição das áreas verdes em cada setor da cidade de Gurupi, foram calculados os IAVS's (Tabela 4), e o setor que apresentou maior índice foi o S4 $(0,04)$, que possui apenas uma área verde (S4A1). O fato de ter o maior IAVS é devido à sua área ser a menor entre os demais $\left(92.186,2 \mathrm{~m}^{2}\right)$, o que veio a contribuir para o aumento do seu índice. Valor semelhante ao de Gurupi foi observado na cidade de Mossoró, 
RN (0,031) (DE ARRUDA et al., 2013), menor em Teresina (0,013) (CARVALHO et al., 2007) e maior em Vinhedo $(0,077)$ (HARDER et al., 2006). Assim, nota-se que o índice varia entre as cidades.

O setor que tem o menor IAVS é o S11 $(0,004)$ (Tabela 4), que se explica por ter apenas uma área verde (S11A1) e esta ser a menor observada no município $\left(807,4 \mathrm{~m}^{2}\right)$ (Tabela 2). Foram identificados valores superiores de IAVS em Teresina (0,013) (CARVALHO et al., 2007) e Mossoró $(0,008)$ (DE ARRUDA et al., 2013), entretanto valor inferior foi observado em Vinhedo (0,001) (HARDER et al., 2006).

Tabela 4. Área verde (AV), área do setor (AS) e Índice de Área Verde por Setor (IAVS) em Gurupi, TO, 2014. Table 4. Green area (AV), sector area (AS) and green area index by Sector (IAVS) in Gurupi, TO, 2014.

\begin{tabular}{crrr}
\hline Setor & $* \mathrm{AV}\left(\mathrm{m}^{2}\right)$ & $* \mathrm{AS}\left(\mathrm{m}^{2}\right)$ & $*$ IAVS $\left(\mathrm{m}^{2}\right)$ \\
\hline S1 & $3.912,0$ & $239.429,7$ & 0,016 \\
S2 & $1.758,3$ & $297.215,3$ & 0,006 \\
S3 & $5.588,4$ & $244.831,7$ & 0,023 \\
S4 & $3.721,5$ & $92.186,2$ & 0,040 \\
S5 & $7.893,8$ & $321.170,6$ & 0,025 \\
S6 & $5.952,4$ & $473.785,2$ & 0,013 \\
S7 & $10.693,5$ & $816.732,2$ & 0,013 \\
S8 & $21.649,8$ & $1.618 .742,0$ & 0,013 \\
S9 & $14.480,6$ & $1.607 .237,0$ & 0,009 \\
S10 & $5.164,1$ & $550.754,8$ & 0,009 \\
S11 & 807,4 & $209.057,5$ & 0,004 \\
S12 & $27.730,0$ & $4.480 .000,0$ & 0,006 \\
\hline
\end{tabular}

A cobertura vegetal das áreas verdes de Gurupi soma um total de $36.297,53 \mathrm{~m}^{2}$. O ICV calculado para a cidade atingiu $0,48 \mathrm{~m}^{2}$ de copa/habitante, entretanto esse índice tende a crescer na cidade, devido à existência de áreas como a S8A1, que é a maior em extensão e tem grande parte de sua arborização ainda jovem, com tendência futura de aumento da área de cobertura vegetal (Figura 2). Valor de ICV semelhante ao de Gurupi foi observado em Teresina (0,47) (CARVALHO et al., 2007) e Vinhedo (0,55) (HARDER et al., 2006), menor em Altamira $(0,18)$ (DE SOUZA et al., 2014) e valor bem maior em Mossoró (9,57) (DE ARRUDA et al., 2013). Dessa forma, observa-se que a cobertura vegetal em Gurupi apresenta similaridade com a maior parte dos municípios pesquisados, entretanto carece de um aumento substancial para atingir patamar maior, como o da cidade de Mossoró, RN. O aumento da ICV de Gurupi pode ser subsidiado não apenas pela criação de novas áreas verdes, mas também pela maior arborização das áreas já existentes.

O PCV das áreas verdes de Gurupi é de $0,13 \mathrm{~m}^{2} \mathrm{de} \mathrm{copa} / \mathrm{m}^{2}$ de área urbana. Esse baixo índice pode ser reflexo do pequeno número de setores que têm área verde na cidade, 12, de um total de 44 existentes, já que o índice considera toda a área urbanizada e não apenas as que possuem áreas verdes. Verificou-se nos trabalhos consultados que ambos apresentaram PCV superior ao de Gurupi: 6,9 (Mossoró) (DE ARRUDA et al., 2013) e 2,86 (Teresina) (ABREU et al., 2012). Isso evidencia a necessidade da criação de áreas verdes nos setores com ausência desses espaços, bem como ações para acréscimo de árvores nas áreas já existentes. Essa necessidade de introdução de novas árvores em áreas carentes de arborização também foi constatada por Silva Filho et al. (2008), já que elas apresentaram espaço disponível. Além disso, essa medida viabilizaria uma melhoria das condições ambientais futuras, com o aumento efetivo da cobertura arbórea e, consequentemente, do bem-estar de sua comunidade.

\section{CONCLUSÕES}

Por meio desta pesquisa, conclui-se que:

- Das 16 praças estudadas em Gurupi, 11 foram classificadas como Parque de Vizinhança e 5 como Parque de Bairro, entretanto a maior parte do território estudado é de é de Parque de Bairro.

- O Índice de Área Verde Total calculado foi de $1,46 \mathrm{~m}^{2} /$ habitante, muito abaixo do ideal.

- Verificou-se Índice de Área Verde para Parque de Vizinhança de 0,58 e Índice de Área Verde para Parque de Bairro de $0,88 \mathrm{~m}^{2} /$ habitante. 
- O setor Jardim São Lucas tem o maior Índice de Área Verde por Setor, com índice influenciado, sobretudo, por uma menor área. O setor Vila Íris tem o menor Índice de Área Verde por Setor, em razão de conter apenas uma praça e esta ser a de menor área.

- Verificou-se um Índice de Cobertura Vegetal de $0,48 \mathrm{~m}^{2}$ de copa/habitante, com possibilidade de aumento, devido a algumas praças terem grande parte de sua arborização ainda jovem.

- Foi observado um Percentual de Cobertura Vegetal de $0,13 \mathrm{~m}^{2}$ de copa $/ \mathrm{m}^{2}$ de área urbana. O baixo índice é reflexo da grande dimensão da área urbana, frente à presença de apenas 12 dos 44 setores com a existência de praças em suas dependências.

\section{AGRADECIMENTOS}

Agradeço à CAPES, pela concessão de bolsa de estudo, bem como a todos os que colaboraram direta ou indiretamente com este trabalho.

\section{REFERÊNCIAS}

ABREU, E. L.; MOURA, H. F. N.; LOPES, D. S.; BRITO, J. S. Análise dos índices de cobertura vegetal arbórea e sub-arbórea das praças do centro de Teresina, PI. In: Congresso Brasileiro de Gestão Ambiental, 3., 2012, Goiânia, GO. Anais... Goiânia: IBEAS, 2012, p. 1-11.

BARGOS, D. C.; MATIAS, L. F. Áreas verdes urbanas: um estudo de revisão e proposta conceitual. Revsbau, Piracicaba, SP, v. 6, n. 3, p. 172-188, 2011.

CARVALHO, A. S.; RODRIGUES, M. D. A.; BRITO, J. S. Índices de área verde e cobertura vegetal das praças dos conjuntos Dirceu Arcoverde I e Dirceu Arcoverde II, Teresina, PI. In: Congresso de Pesquisa e Inovação da Rede Norte-Nordeste de Educação Tecnológica, 2., 2007, João Pessoa, PB. Anais... João Pessoa: Connepi, 2007.

CAVAlHEIRO, F.; DEL PICCHIA, P. C. D. Áreas verdes: conceitos, objetivos e diretrizes para o planejamento. In: $1^{\circ}$ CONGRESSO BRASILEIRO SOBRE ARBORIZAÇÃO URBANA. Encontro Nacional sobre Arborização Urbana, 4., 1992. Vitória - ES. Anais... Vitória, 1992. p. 29-38.

CAVAlHEIRO, F. O planejamento de espaços livres: o caso de São Paulo. Silvicultura/Inst. Florestal, São Paulo, v. 16A, n. 3, p. 1819-1830, 1982.

COSTA, C. S. Áreas Verdes: um elemento chave para a sustentabilidade urbana. Arquitextos, São Paulo, v. 11, 2010, $126 \mathrm{p}$.

COSTA, R. G. S.; COLESANTI, M. M. A Contribuição da percepção ambiental nos estudos das áreas verdes. RA'E GA. Curitiba: UFPR, v. 22, p. 238-251, 2011.

DA SILVA, R. R.; FREITAS, G. A.; SIEBENEICHLER, S. C.; MATA, J. F.; CHAGAS, J. R. Desenvolvimento inicial de plântulas de Theobroma grandiflorum (Willd. ex Spreng.) Schum. sob influência de sombreamento. Acta Amazonica, v. 37, n. 3, p. 365-370, 2007.

DE ARRUDA, L. E. V.; SILVEIRA, P. R. S; VALE, H. S. M.; DA SILVA, P. C. M. Índice de área verde e de cobertura vegetal no perímetro urbano central do município de Mossoró, RN. Revista Verde de Agroecologia e Desenvolvimento Sustentável, Mossoró, RN, v. 8, n. 2, p. 13-17, 2013.

DE SOUZA, O. P. S.; DE SOUZA, P. T. S.; DE FREITAS, A. D. D.; PARAENSE, V. C.; SOUZA, D. V. Indicadores de área verde e cobertura arbórea para as praças do município de Altamira, Pará. Enciclopédia Biosfera, Goiânia, v. 10, n. 18, p. 1955-1962, 2014.

DOS SANTOS, A. C. M. F. Uso social de parques públicos - estudo de caso do Parque Roberto Burle Marx - parque da cidade - São José dos Campos, SP. 2011. 95 f. Dissertação (Mestrado em Planejamento Urbano e Regional) - Instituto de Pesquisa e Desenvolvimento, Universidade do Vale do Paraíba, São José dos Campos.

FUADY, M.; DARJOSANJOTO, E. T. S. Tropical ecological city concept for banda aceh to become sustainable after tsunami disaster. J. Appl. Environ. Biol. Sci, v. 2, n. 8, p. 428-433, 2012.

GOOGLE, Programa Google Earth, Versão 7.1.2.2041. 2013. 
GURUPI. Lei complementar n $^{\text {0 } 009, ~ d e ~} 31$ de dezembro de 2007. Institui o Plano Diretor de Desenvolvimento Sustentável de Gurupi e dá outras providências. Disponível em: <http://www.gurupi.to.leg.br/legislacaomunicipal>. Acesso em: 31 jan. 2015.

GURUPI. Plano diretor: mapa multifinalitário. 2016. Disponível em: <http://www.gurupi.to.gov.br/?page= plano-diretor>. Acesso em 03 Mai. 2016.

HARDER, I. C. F.; RIBEIRO, R. C. S.; TAVARES, A. R. Índices de área verde e cobertura vegetal para as praças do município de Vinhedo, SP. Revista Árvore, Viçosa, MG, v. 30, n. 2, p. 277-282, 2006.

INSTITUTO BRASILEIRO DE GEOGRAFIA E ESTATÍSTICA (IBGE). Censo Demográfico 2010: resultados do universo - indicadores sociais municipais. 2010. Disponível em: <http://www.cidades.ibge.gov.br/xtras/temas. php?lang=\&codmun=170950\&idtema=79\&search=tocantins\% 7Cgurupi \%7Ccenso-demografico-2010:-resultadosdo-universo-indicadores-sociais-municipais>. Acesso em: 19 jan. 2015.

KARAGIANNIS, S.; ANTHOPOULOS, L.; ASPRIDIS, G.; SDROLIAS, L.; POLYKARPIDIS, A. Green urban space utilization for mild ICT-based touristic activities: the case of Pafsilipo Park in Greece. Journal of Environmental and Tourism Analyses, v. 2, n. 1, p. 83-96, 2014.

LIMA, V.; AMORIM, M. C. C. T. A importância das áreas verdes para a qualidade ambiental das cidades. Formação, Presidente Prudente, SP, v. 1, n. 13, p. 139-165, 2011.

LONDE, R. P.; MENDES, P. C. A influência das áreas verdes na qualidade de vida urbana. Hygeia, Uberlândia, MG, v. 10, n. 18, p. 264-272, 2014.

LUCON, T. N.; FILHO, J. F. P.; SOBREIRA, F. G. Índice e percentual de áreas verdes para o perímetro urbano de Ouro Preto, MG. Revsbau, Piracicaba, SP, v. 8, n. 3, p. 63-78, 2013.

MARTINI, A.; BIONDI, D.; BATISTA, A. C.; ZAMPRONI, K.; VIEZZER, J.; GRISE, M. M.; NETO, E. M. L. Percepção da população sobre o conforto térmico proporcionado pela arborização de ruas de Curitiba, PR. Floresta, v. 44, n. 3, p. 515-524, 2014.

NOOR, N. M.; ABDULLAH, A.; MANZAHARI, M. N. H. Land cover change detection analysis on urban green area loss using GIS and remote sensing techniques. Planning Malaysia, v. 11, p. 125-138, 2013.

NUCCI, J. C. Qualidade ambiental \& adensamento urbano: Um estudo de ecologia e planejamento da paisagem aplicado ao distrito de Santa Cecília (MSP). São Paulo: Humanitas, 2001.

PIRES, N. A. M. T.; MELO, M. S.; OLIVEIRA, D. E.; SANTOS, S. X. A arborização urbana do município de Goiandira/GO - caracterização quali-quantitativa e propostas de manejo. Revsbau, Piracicaba, SP, v. 5, n. 3, p. 185-205, 2010.

RIBEIRO, J. B.; BORGO, M.; MARANHÃO, L. T. Áreas protegidas de Curitiba (PR, Brasil) como sumidouros de $\mathrm{CO}_{2}$. Floresta, v. 43, n. 2, p. 181-190, 2013.

SECRETARIA DO PLANEJAMENTO E DA MODERNIZAC̨ÃO DA GESTÃO PÚBLICA (SEPLAN). Perfil socioeconômico dos municípios do estado do Tocantins. 2013. Disponível em: <http://www.seplan.to.gov.br/Portal/faces/index_2.xhtml>. Acesso em 10 nov. 2014.

SILVA FILHO, D. F.; MEIRA, A. M.; SETTE JR., C. R.; ALEXANDRINO, E. R.; NOGUEIRA, C. L.; GUARALDO, E.; OliVATTO, F.; ROLlO, F. M. A.; PARRA, J.; CHAGAS, M. P.; BIANCHI, M.; GABRIEL, M. V.; CELIDONIO, R. M. G. S.; FLORSHEIM, S. M. B; DA COSTA, T. J. Levantamento do potencial de arborização e proposta para três bairros no município de Piracicaba/SP, Brasil. Revsbau, v. 3, n. 4, p. 20-39, 2008.

SINGH, V. S.; PANDEY, D. N.; CHAUDHRY, P. Urban forests and open green spaces: lessons for Jaipur, Rajasthan, India. RSPCB Occasional Paper, v. 1, p. 1-23, 2010.

TOCANTINS. Atlas do Tocantins: subsídios ao planejamento da gestão territorial. Palmas: Seplan, 6. ed. rev. atu. 2012.

FLORESTA, Curitiba, PR, v. 46, n. 3, p. 353 - 361, jul. / set. 2016

Silva, A. D. P. da et al.

ISSN eletrônico 1982-4688

DOI: $10.5380 /$ rf.v46i3.40052 